\title{
Professor agente de decisão curricular: uma scriptura em Portugal
}

The Teacher as an Agent of Curricular Decision: A Policy in Portugal Profesor agente de decisión curricular: una scriptura en Portugal

Artigo de investigação científica e tecnológica | Research article | Artículo de investigación

Data de recepção: 28 de novembro de 2018 Data de aceitação: 20 de maio de 2019 Data de disponibilidade em linha: julho de 2020

doi: 10.11144/Javeriana.m13.padc

Adriana Cavalcanti dos Santos adricavalcanty@hotmail.com

Universidade Federal de Alagoas (UFAL), Brasil ORCID: http://orcid.org/0000-0002-4556-282X

CARLINDA LeITE carlinda@fpce.up.pt ClIE-Centro de Investigação e Intervenção Educativas, Faculdade de Psicologia e de Ciências da Educação, Universidade do Porto, PoRTUgal D ORCID: http://orcid.org/0000-0001-9960-2519

Para citar este artículo | To cite this article Cavalcanti dos Santos, A. \& Leite, C. (2020). Professor agente de decisão curricular: uma scriptura em Portugal. magis, Revista Internacional de Investigación en Educación, 13, 1-21. doi: 10.11144/Javeriana.m13.padc 


\title{
Resumo
}

$\mathrm{O}$ artigo elege como foco o entrelaçamento entre discursos acadêmicos e políticos, que apontam para a agência dos professores, e discursos da prática, proferidos por professores e gestores educativos que aderiram, em Portugal, à medida política do Projeto de Autonomia e Flexibilização Curricular. A análise desses discursos, recolhidos por entrevistas semidiretivas, aponta para fatores contextuais que dão forma ou estabelecem limites aos professores assumirem o seu poder de agência de decisão curricular, o que permite concluir que a autonomia e flexibilidade do currículo concedidas, no campo do discurso político, não garantem per se o poder de agência dos professores.

\section{Palavras-chave}

Agência docente; currículo; educação básica; política educacional

\begin{abstract}
This article takes as the core element the relationship between the academic and political discourses addressing the teacher agency and the discourses on the practice by those teachers and education promoters who worked in the Portuguese policy of Curricular Autonomy and Flexibility Project. The analysis of the discourses - gathered through semi-directed interviews - accounts for contextual factors that shape or set the limits to the teacher's agency power in the curricular decision-making processes. All the foregoing leads to the conclusions that the autonomy and flexibility of the curriculum enabled by the political discourse does not ensure per se the agency power of the teachers.
\end{abstract}

\section{Keywords}

Teaching agency; curriculum; basic education; educational policy

\section{Resumen}

El artículo elige como elemento central la relación entre los discursos académicos y políticos, que apuntan a la agencia de los docentes, y los discursos sobre la práctica por parte de los profesores y gestores educativos que se sumaron, en Portugal, a la política del Proyecto de Autonomía y Flexibilidad Curricular. El análisis de los discursos, recogidos por entrevistas semidirectivas, da cuenta de factores contextuales que dan forma o establecen límites a los profesores en su poder de agencia en los procesos de decisión curricular. Lo anterior permite concluir que la autonomía y flexibilidad del currículo planteada desde el discurso político no garantiza per se el poder de agencia de los docentes.

\section{Palabras clave}

Agencia docente; currículo; educación básica; política educativa 
Descripción del artículo | Article description

Este artigo é parte dos estudos de uma investigação de PósDoutoramento da autora 1, Políticas e metas curricular para educação básica no Brasil e em Portugal: implicações no currículo e na formação docente, desenvolvida na Faculdade de Psicologia e de Ciências da Educação da Universidade do Porto (FPCEUP), sob a orientação da professora catedrática Carlinda Leite. Este trabalho foi financiado (parcialmente) por Fundos Nacionais através da FCT-Fundação para a Ciência e a Tecnologia no âmbito do projeto estratégico do CIIE, com a referência UID/CED/00167/2013.

\section{Introdução}

Os discursos acadêmicos e políticos que defendem concepções epistemológicas de currículo como construção das interações cotidianas entre o conhecimento científico e os conhecimentos prévios dos alunos, respeitando as suas diversidades e experiências de vida, têm vindo a deslocar o lugar do professor, concebido como mero executor de um currículo prescrito pelo governo central, para o de agente de decisões curriculares (Priestley, Biesta \& Robinson, 2013, 2015; Leite \& Fernandes, 2010). Com esta intervenção dos professores no currículo escolar, espera-se a criação de condições que assegurem a igualdade de oportunidades de sucesso para todos os alunos, concretizadora de uma justiça curricular e social (Connell, 1999, 2012; Sampaio \& Leite, 2015, 2018). Em outras palavras, reconhece-se que o papel que os professores assumem no currículo (Leite \& Fernandes, 2010; Priestley et al., 2013, 2015; Parra-Mosquera, 2016) e nos processos do seu desenvolvimento influencia os resultados dos alunos e as suas oportunidades de aprendizagem.

Tendo por referência esta ideia, foi desenvolvido o estudo a que se reporta este artigo, que elege como objeto de análise percepções de professores e elementos responsáveis pela gestão de escolas da educação básica, em Portugal, envolvidos num projeto que os reconhecem como agentes de decisão curricular. Do ponto de vista teórico, o estudo apoia-se em concepções que consideram a escola como instituição curricularmente inteligente (Leite, 2003), isto é, com um potencial para intervir nas situações com que convive, e os professores no seu poder de agência, embora dependentes de fatores contextuais que a favorecem ou the estabelecem limites.

Este projeto, designado por "Projeto de Autonomia e Flexibilização Curricular" (PAFC), foi proposto em regime de experiência no ano escolar de 2017-2018 (Despacho n. ${ }^{\circ}$ 5908/2017, de 5 de julho de 2017) e, a partir 
do ano letivo 2018-2019 passou a ser extensivo a todas as escolas do país (Decreto-Lei n. ${ }^{\circ}$ 55/2018, de 6 de julho de 2018). No discurso político da legislação que institui este projeto, os princípios de autonomia e flexibilidade curricular são entendidos como "a faculdade conferida à escola para gerir o currículo dos ensinos básico e secundário, partindo das matrizes curriculares-base, assente na possibilidade de enriquecimento do currículo com os conhecimentos, capacidades e atitudes" (Decreto-Lei n. ${ }^{\circ}$ 55/2018, de 6 de julho de 2018, p. 2930) dos alunos. Na concretização desta faculdade conferida às instituições escolares, isto é, no contexto de prática (Ball, 2002, 2005), a legislação define que, entre $0 \%$ e $25 \%$ da carga horária dos alunos é da responsabilidade de cada escola, e dependente do seu projeto curricular. Concebe ainda que os professores, na concretização do currículo, tenham em consideração as especificidades dos contextos e dos alunos a quem ele se destina (Decreto-Lei n. ${ }^{0}$ 55/2018, de 6 de julho de 2018).

Como se depreende, esta medida política, nos princípios de autonomia e flexibilização curricular que a orientam, espera que os professores realizem processos de contextualização (Sampaio \& Leite, 2018) e de diferenciação curricular (Trindade \& Cosme, 2014). Como limites a esta autonomia das escolas e ao poder de agência dos professores, a legislação determina que as competências a alcançar pelos alunos sejam as definidas no Perfil dos Alunos à Saída da Escolaridade Obrigatória (Despacho n. ${ }^{\circ}$ 6478/2017, de 26 de julho de 2017).

A adesão das escolas portuguesas a essa "nova" política curricular tem na sua intenção constituir uma medida de resolução de problemas relacionados com o insucesso e o abandono escolares geradores de desigualdades sociais. Na sua matriz conceptual, esta medida política, que reconhece poderes às escolas, segue uma política que ocorreu em Portugal na transição para o séc. XXI (Leite, 2005) e que iniciou processos fundados em princípios flexibilização e autonomia curricular. Nessa altura, essa política pretendeu criar rupturas com a tradição existente em Portugal de um currículo fortemente centralizado, prescrito pelo governo, para ser concretizado de igual forma por todas as escolas, independemente dos seus contextos, recursos ou problemas. Nesta descentralização do governo para as escolas, tanto na medida que aconteceu na transição de séculos como agora no PAFC, é igualmente reconhecida a importância da participação da comunidade local nas decisões que tornem a escola mais inclusiva, isto é, por um lado, acredita-se que ela é favorecida por esta participação e, por outro, essas instituições e demais agentes sociais são responsabilizadas pela formação dos seus cidadãos (Freire, 2003; Gadotti, 2010).

Foi tendo por referência estas ideias e a medida política PAFC que se realizou um estudo que analisa, a partir dos discursos de responsáveis pela 
gestão de Agrupamentos de Escolas e de professores do 1. ${ }^{\circ}$ ciclo da Educação Básica, fatores dos contextos da prática que dão forma ou estabelecem limites aos professores para assumirem o seu papel de agentes de decisão curricular. O estudo orienta-se pela pergunta: qual a concepção de professores e gestores de Agrupamentos de Escolas sobre os fatores contextuais que dão forma ou estabelecem limites aos professores para se assumirem como agentes de decisões curriculares, isto é, para concretizarem o discurso da política curricular portuguesa PAFC?

No quadro desta interrogação, o artigo, na sua estrutura, apresenta uma caracterização do discurso acadêmico, no que diz respeito aos professores serem entendidos como agentes de decisão curricular, explicita o procedimento de pesquisa seguido no estudo empírico e interpreta perspectivas de responsáveis pela gestão de escolas e de professores do $1 .^{\circ}$ ciclo da Educação Básica, sobre este postulado, no contexto da política curricular PAFC em curso em Portugal. O artigo termina tecendo as considerações finais que sintetizam os fatores que dão forma e limitam o movimentum que concebe as escolas como instituições curricularmente inteligentes e os professores como agentes de decisões curriculares.

\section{O poder de agência dos professores: um tear em construção}

Num cenário de globalização (Robertson \& Dale, 2014), neste séc. $X X I$, assiste-se a uma tensão entre processos de regulação de políticas curriculares (Pacheco \& Sousa, 2018; Leite, 2005) e processos de autonomia (Lima, 2014; Barroso, 2004) que apontam muitas vezes para mudanças e inovações nos modelos de organizações escolares, nos processos de configuração e desenvolvimento do currículo (Moreira, 2013; Leite, 2005) e de avaliação das aprendizagens dos alunos (Marinho, Leite \& Fernandes, 2017). Subjacente a esta orientação está a ideia de que a escola, enquanto instituição educativa e curricularmente inteligente (Leite, 2005) possa preparar os alunos para as demandas da complexidade das sociedades em constantes mudanças.

Nesse cenário de complexidades e incertezas, é reconhecida a importância de aos professores ser delegado o poder de agir para a mudança e a inovação curricular, isto é, de assumirem o seu poder de agência (Priestley et al., 2015), na configuração do currículo no cotidiano (Ferraço, 2017). No movimentum de repensar o papel da escola na concretização de uma justiça social e curricular (Connell, 1999, 2012; Sampaio \& Leite, 2018), a concepção de professor como agente de decisão curricular tem vindo progressivamente a assumir-se como uma temática central nos discursos 
acadêmicos que reconhecem, nos estudos das políticas curriculares, que aos professores, em contextos de prática (Ball, 2002, 2005), devem ser garantidas oportunidades de flexibilização curricular (Leite, 2005) alinhadas ao conceito de agência.

O conceito de agência (agency) pode ser entendido como a "capacidade humana individual de agir independentemente e fazer suas próprias escolhas" (Mainardes \& Marcondes, 2009, p. 315). É nesse sentido que Priestley et al. $(2013,2015)$ postula que os professores, nos discursos das políticas educacionais, são entendidos como agentes de mudança, embora nos referidos discursos possamos encontrar inúmeras contradições e tensões. Para este autor, o conceito de agência (agency) estaria relacionado com a capacidade dos indivíduos agirem reflexivamente em contextos de prática, limitados pelos enquadramentos impostos pelos ambientes sociais e materiais, isto é, pelos contextos de influências (Ball, 2002, 2005). Agency pode ser entendida também como as estratégias pelas quais os atores "critically shape their responses to problematic situations" (Biesta \& Tedder, 2006, p. 11).

Ampliando esta discussão, os professores, na posição de agência (agency), e embora enquadrados por políticas neoliberais (Ball, 2005; Castillo-Alemán, 2012), assentes na busca de melhores resultados/desempenhos dos alunos, teriam a responsabilidade de recorrer a processos que promovam o sucesso de todos eles. Nesta posição, concordamos com Bolívar (2012) quando refere que "o núcleo da mudança educativa situa-se, não a nível micro da sala de aula [...] mas no nível intermédio que são as condições organizacionais do estabelecimento de ensino" (Bolívar, 2012, p. 18), isto é, reconhecemos que os professores, para agirem enquanto decisores curriculares, precisam de políticas e de organizações que a favoreçam. Precisam de não ficar "aprisionados" às concepções de currículo prescrito a nível governamental e aos limites impostos por algumas das condições efetivas de trabalho. Por outro lado, para os professores usarem o seu poder de agência (agency) têm de conceber o currículo como uma construção e reconfiguração cotidiana (Ferraço, 2017) e, simultaneamente, fazerem-na. Como é referido por Priestley et al. (2015, p. 4), "agency, in other words, is not something that people can have - as a property, capacity or competence- but is something that people do".

Nesta concepção do papel dos professores, e em linha com o conceito de escola curricularmente inteligente (Leite, 2005), acredita-se que estes, recorrendo às suas experiências pessoais e profissionais, são capazes de identificar os problemas reais com que se confrontam nos cotidianos escolares e de, em função deles, definir as melhores formas de agir. As possibilidades que existem para os professores usarem o seu poder de 
agência (agency) foi o que nos motivou para a pesquisa que neste artigo se apresenta. Num cenário de complexidades, o poder de agência (agency) do professor "denotes a quality of the engagement of actors with temporal-relational contexts-for-action, not a quality of the actors themselves" (Priestley et al., 2015, p. 3).

Pensar o poder de agência (agency) dos professores numa lógica vertical de um processo de mudança de concepções, em que lhes é concedida autonomia e decisão para usarem até $25 \%$ do tempo curricular, não significa que estes consigam imprimir mudanças efetivas e significativas na escola. Como sustentam os autores atrás referidos, os professores, enquadrados pelo discurso da política curricular e pelos contextos de práticas, podem apenas reproduzir os padrões de comportamentos e ações predefinidos, no pretexto de evitar constrangimentos relacionais ou institucionais. Este foi também um dos aspetos tido em consideração no estudo que a seguir se apresenta.

\section{Procedimentos metodológicos}

Com o propósito de responder à pergunta de pesquisa atrás enunciada (qual a concepção de professores e gestores de Agrupamentos de Escolas, sobre os fatores contextuais que dão forma ou estabelecem limites aos professores para se assumirem como agentes de decisões curriculares, isto é, para concretizarem o discurso da política curricular portuguesa PAFC), foi realizada uma investigação de natureza qualitativa (Vilelas, 2009), apoiada no método de análise das políticas educacionais seguido por Ball (2002, 2005) relativo ao contexto da enunciação política e ao contexto da prática, ambos marcados pelos seus contextos de influência.

Os discursos acadêmicos, sobre os pressupostos do lugar do professor como agente de decisão curricular, discutidos no início deste artigo, foram guias para analisar as opiniões dos entrevistados que representam o contexto da prática. Desses entrevistados fazem parte responsáveis pela gestão de dois Agrupamentos de Escolas e professores do 1. ${ }^{\circ}$ ciclo da Educação Básica inseridos em cada um deles. As entrevistas, do tipo semi-diretivo (Seidman, 2013), focaram fatores contextuais que dão forma ou estabelecem limites para os professores se assumirem como agentes de decisões curriculares, a partir da medida política do PAFC.

No que se refere aos Agrupamentos de Escolas loci de investigação, um pertence à rede Território Educativo de Intervenção Prioritária (TEIP), localizado na grande Porto-Portugal, e um outro não TEIP localizado nos arredores do Porto-Portugal. Nesse contexto, foram selecionados professores do $10^{\circ}$ ciclo da Educação Básica em virtude do Projete de Investigação 
de Pós-doutoramento, de uma das autoras, se desenvolver nesse nível de ensino no âmbito do Centro de Investigação e Intervenção Educativa (CIIE).

O procedimento de análise das opiniões expressas pelos entrevistados, na perspectiva dialógica da linguagem e de significação do discurso (Bakthin, 1992), contemplou e deu voz às perspectivas destes agentes educativos do contexto da prática (Ball, 2002, 2005) e que correspondem a: uma professora, que simultaneamente assume a função de coordenadora do PAFC no Agrupamento (referenciada por PC1); uma coordenadora do

1. ${ }^{\circ}$ Ciclo da Educação Básica (referenciada por CA); um adjunto da direção (referenciado por AD), e quatro professores desses Agrupamentos (referenciados por PPC1, PPC2, PPC3, PPC4).

A recolha dos dados, correspondentes a produções discursivas que traduzem as opiniões desses agentes educativos, realizou-se in loco, em 2018, apoiada em um guião que tinha por objetivo mapear percepções sobre condições que potenciam e/ou que limitam a concretização do poder de agência dos professores. Estes entrevistados, entre outras questões, e a depender da posição que ocupam na escola, foram interrogados sobre: Como é que a escola e os professores se colocam frente ao PAFC? Esta medida política tem implicado mudanças e inovação das práticas curriculares dos professores e no seu poder de agência (agency) de decisão curricular?

As respostas dos entrevistados, que traduzem as suas percepções sobre estas questões, foram interpretadas pela técnica de análise de conteúdo (Bardin, 2009). É com base nessa análise que são apresentadas as percepções desses professores e responsáveis pela gestão de escolas, e tecidas as considerações finais da investigação.

\section{Apresentação e discussão dos dados}

As percepções dos responsáveis de escolas e dos professores, analisadas pela técnica de análise de conteúdo, foram organizadas em duas grandes categorias: fatores que dão forma ao saber-fazer curricular do professor como agente de decisão curricular; fatores que limitam o poder de agência do professor. A primeira categoria foi desdobrada em três subcategorias: concepções de/sobre o princípio de flexibilização do PAFC; professor como agente de decisões curriculares; a "nova" política curricular. É em função destas categorias e subcategorias de análise que a seguir são apresentados e interpretados os sentidos e significados enunciados pelos entrevistados, e que desvelam as suas percepções sobre o papel de agência (agency) de decisões curriculares no contexto do PAFC, instituído pela política curricular em Portugal. 


\section{Fatores que dão forma ao saber-fazer curricular do professor como agente de decisão curricular}

Como foi indiciado, as práticas curriculares desenvolvidas pelos professores revelam muitas vezes as suas concepções de educação, de escola e de currículo, assim como de outros conceitos que implicam e estão implicados no seu saber-fazer docente e no seu poder de agência, tal como são clarificados nos pontos seguintes.

\section{Concepções de/sobre o princípio de flexibilização do PAFC}

Os princípios de autonomia e flexibilidade são entendidos no PAFC como meios que permitem às escolas melhorar a qualidade do trabalho educativo, pela possibilidade do professor se colocar enquanto agente de decisão curricular, e de reconfigurador do currículo (Leite \& Fernandes, 2010). É também nessa direção que um dos professores a entende quando refere que

o projeto de flexibilização [PAFC] é muito interessante. E é extremamente útil. É, se formos a ver, mais adequado ao perfil do aluno. É mais justo em termos de avaliação, e de respeito pela progressão de cada aluno. Respeita o seu desenvolvimento natural. E não obriga a ser mais do que aquilo que pode ser. Respeita muito bem a individualidade. E respeita também a nossa ação (PPC1).

O poder de agência de decisão curricular dos professores, que se espera venha a ter efeitos na promoção da justiça social e curricular na escola (Connell, 1999, 2012; Sampaio \& Leite, 2015, 2018), e que é defendido no âmbito do discurso político que instituiu o PAFC, para alguns professores, não se coloca com uma nova orientação. Afirmam alguns dos entrevistados que o que é proposto já o faziam em contexto de prática. Refere um dos entrevistados: "seria um projeto piloto, a iniciar no nosso Agrupamento de Escolas. É evidente que no início é tudo novo. No entanto, há muitas coisas, variadíssimas coisas, que já fazemos, mas não lhe damos esse nome" (PPC2). Na concretização deste poder de agência, afirma outro dos entrevistados,

a flexibilidade tem uma parte positiva, o fato de criar projetos, o fato de pôr as pessoas a trabalhar colaborativamente, faz com que basta haver um ou dois professores que puxem para esse lado, os outros são capazes de ir por arrasto (AD). 
Embora não seja reconhecido que o PAFC introduziu grandes mudanças, consideram estes entrevistados que a escola é pensada como uma instituição responsável por gerir o currículo, como reconhece a professora:

Foi dada às escolas autonomia para gerir o currículo de forma a trabalhar a medida mais importante para a promoção de sucesso escolar que é a diferenciação pedagógica. É necessário ter tempo para gerir o currículo, atendendo aos diferentes ritmos e às dificuldades dos alunos. Tem sido feita a verificação do que é essencial, permitindo a consolidação efetiva das aprendizagens (PPC2).

Segundo esta entrevistada, há uma autonomia curricular relativa, pois os professores são orientados para garantir as Aprendizagens Essenciais e cumprir Metas curriculares. É em tensão com esta ideia que no discurso da política curricular, as mudanças e a inovação estão ancoradas numa cultura escolar de autonomia e de trabalho em equipe, ao nível do conselho de docentes e de turma. Este discurso legal aponta para o princípio da interdisciplinaridade em que as disciplinas "cruzam o que deve ser ensinado", e onde as ações curriculares e estratégicas "devem ser concretizadas para que os alunos aprendam melhor e de forma mais significativa" (Despacho n. ${ }^{\circ}$ 6944-A/2018, de 19 de julho de 2018). Em diálogo com estes princípios enunciados no discurso político, um professor que trabalha em um Agrupamento que pertence à rede Território Educativo de Intervenção Prioritária (TEIP), sobre as orientações do PAFC, afirma:

Temos autonomia para flexibilizar o currículo, para dar importância a uns conteúdos em detrimento de outros. Neste meio em que nós estamos, Agrupamento TEIP, é muito importante. Porque nós temos crianças em que o currículo tem que ser muito alternativo e específico. Temos que adaptá-lo ao meio, que é desfavorecido a nível social. É mais fácil trabalhar com a flexibilização (PPC4).

Como se depreende, o entendimento do currículo enquanto projeto que tem de ganhar sentido face às características dos alunos e do meio é facilitado quando as escolas já tinham uma cultura institucional próxima das orientações do PAFC, e que, em Portugal, corresponde às escolas TEIP. Estas escolas, "pelas caraterísticas da população escolar que as frequenta se insere no que é designado por Território Educativo de Intervenção Prioritária, política que tem desenvolvido práticas de participação através da educação para a cidadania" (Leite, Fernandes \& Marques da Silva, 2013, pp. 35-36). Dessa experiência, mas ainda considerando que se está longe da sua concretização, é exemplo o referido por uma das entrevistadas: "O PAFC tem 
muito a ver com o que eu acredito da escola, mas acho que a escola em Portugal evoluiu muito pouco" (PC).

À medida que o discurso do projeto de autonomia e flexibilização curricular se move para o interior da escola, nova posição surge, isto é, a referida política é interpretada na sua relação com o conceito de agência de decisão curricular, como se infere pelo discurso da professora: "é pela flexibilização do currículo prescrito a nível nacional que vamos conseguir combater algum insucesso. Podemos flexibilizar, então vamos dar prioridade ao essencial" (PPC3).

Em um dos Agrupamentos de Escolas, loci da investigação, foi referido: "Todas as mudanças com implementação do PAFC ocorreram num contexto de grande tensão em que uma grande parte dos professores percebeu o que se pretende e que tem a ver com dar sentido às aprendizagens" (CA). Realce-se ainda existir um consenso nas opiniões dos entrevistados a que se refere esta investigação e que aponta para a necessidade de mudança e inovação curricular, respeitando os conhecimentos e processos de aprendizagens dos alunos. Neste sentido, o recurso ao poder de agência de decisão curricular permite aos professores olhar para as especificidades dos contextos e diversidades dos alunos como aliados para a construção de um currículo mais inclusivo.

\section{Professor como agente de decisão curricular}

As experiências de mudança curricular, em curso em Portugal, como já referimos, estão ligadas ao entendimento do professor como agente de decisão curricular. Este entendimento pode revestir-se de diferentes formas de conceber a organização do currículo e a sua gestão, quer ao nível da escola, quer do que se passa na sala de aula (Pacheco \& Sousa, 2018). Pressupõe, por isso, que os professores, perante as situações reais com que convivem, contextualizem e adaptem o currículo prescrito para todo o país pelo Ministério da Educação (Leite, 2005; Leite \& Fernandes, 2010).

Os princípios de autonomia e flexibilização curricular, ao desafiarem os professores a ajustarem as suas ações didáticas, implicam, em certa medida, que sejam seguidos processos na linha do que é expresso por uma das entrevistadas: "É no fundo deixá-los [alunos] um pouco guiar as aulas, guiar o programa, os conteúdos programáticos, orientando sempre [o currículo]. Mas tentando que sejam eles a chegarem ao objetivo" (PPC1). Nesta posição, vemos o entendimento de um "currículo organizado em torno da experiência, da cultura e das necessidades dos membros menos favorecidos da sociedade, em vez dos mais favorecidos" (Connell, 2012, p. 682), isto é, um currículo cotidiano (Ferraço, 2017) construído no entremeio entre teoria e experiência (Young, 2014). Por outro lado, quando os professores 
tomam decisões curriculares que pretendem garantir melhores aprendizagens a todos os alunos, e tal como é referido por Leite \& Fernandes (2010, p. 200), estão a contribuir para uma "escola que se desafia continuamente a si própria e que procura, envolvendo todos, instituir uma dinâmica interna e externa conducente à melhoria da qualidade da educação das crianças e dos jovens que acolhe". É em sentido idêntico que Biesta \& Tedder (2006), assim como Priestley et al. $(2013,2015)$, em análise das possibilidades da educação escolar contemplar a diversidade que caracteriza as populações escolares, aprofundam o conceito de agência dos professores. Em nossa opinião, estas são posturas que se apresentam como a "chave" para abrir a escola a práticas curriculares mais inclusivas. No que ao projeto PAFC dis respeito, indícios da construção de uma cultura de colaboração podem ser inferidos a partir do que é dito pelos professores:

Numa fase inicial isso [a partilha] foi fundamental, porque alguns de nós fomos apanhados de paraquedas, e não estava previsto [o PAFC]. Essas reuniões aconteceram no início do ano letivo, primeiro período e início do segundo período. E existia um tronco comum, um tema que era tronco comum, e todos seguimos esse tema. E partilhávamos os resultados (PPC1).

Chegou-nos a proposta da direção para fazermos partilha, no fundo fazer uma síntese do que tem sido o nosso trabalho no projeto [PAFC] para apresentar ao Departamento. Fizemos essa apresentação, partilhamos. Agora, há várias opiniões: há aqueles colegas que acham que realmente se deve partilhar, há outros que acham que como nós não tivemos orientações, também não temos que estar a dar (PPC2).

Apesar de não haver consenso entre os professores sobre a relevância da partilha durante o processo de adesão ao PAFC, a bibliografia académica tem reconhecido a importância da cultura de colaboração. Como foi referido em outro estudo (Leite \& Lascano-Pinto, p. 72),

o trabalho colaborativo entre os professores tem vindo a ser considerado uma mais-valia quando apropriado pelas instituições educativas, nomeadamente pelas possibilidades que oferece para os professores enfrentarem os inúmeros desafios que a docência coloca face ao objetivo de promoverem não só a aprendizagem dos alunos como a sua extensão e êxito.

Retomando a análise focada na posição dos professores como agentes de decisão curricular, ela implica mudanças significativas na forma de entender e gerir o movimentum e a construção do currículo, como desvela o 
que foi enunciado pelos professores: "A gestão é feita de forma normal e natural, respeitando à vontade dos alunos, e orientando as aprendizagens para interesses particulares dos alunos" (PPC1). "Eu tento flexibilizar o currículo de acordo com os alunos que tenho. Mas, de alguma forma, tento cumprir com o programa. Adapto as aulas à turma. É essa a gestão e a flexibilização curricular" (PPC2).

Como se depreende, embora os professores se encontrem enquadrados por orientações prescritivas que têm de seguir, e de que são exemplo as Metas curriculares a cumprir, diante das especificidades dos contextos em que trabalham, começam a propor adaptações, como relata o professor:

Houve a preocupação da direção em trazer o professor [...] e os colegas da DGEstE para virem falar sob o PAFC. Achei importante, porque sentíamonos perdidos. E, inicialmente, uma certa vergonha, timidez. As reuniões iniciais eram todos à espera que alguém perguntasse. Depois começamos a perceber que a dúvida daquele era a minha dúvida, e começamos a partilhá-las. Há também, no site da DGEstE, webinars sobre o PAFC que são essenciais (PPC2).

Percebe-se que, no processo de entendimento da política curricular do PAFC, que garante no discurso político o poder de agência dos professores, os encontros de formação continuada no contexto de uma cultura de colaboração podem vir a reduzir as incertezas e os constrangimentos dos docentes, de modo a garantir o estabelecimento de limites comuns que definam quais as ações docentes que podem ser realizadas em contextos locais.

Em síntese, no contexto de uma ética profissional, as relações de interação entre os agentes da escola podem ser potencializadas pelas suas capacidades pessoais (habilidades, conhecimentos teóricos e experiências práticas) e as suas motivações podem constituir fatores que alargam ou restringem o poder de agência dos professores. 


\section{A "nova" política curricular}

Como já atrás referimos, os entrevistados foram questionados sobre a política curricular que enquadra o PAFC. São as suas opiniões, e que expressam reflexões críticas construídas a partir de suas lentes sobre a concepção do "novo" enquadramento curricular do PAFC em Portugal, que aqui apresentamos. Para Pacheco \& Souza (2018, p. 133), esta política reintroduz no país a perspectiva de reforma, "sustentando o ciclo de reforma curricular parcial, bastante episódica e superficial nos seus conteúdos, substituída, em 2017, pelo ciclo de inovação pedagógica, com base numa maioria parlamentar (XXI Governo Constitucional)" [grifos do autor]. No entanto, segundo um dos entrevistados, para além do tempo curricular garantido ao professor para fazer uso do seu poder de agência de decisão curricular, esta medida política não introduziu grandes mudanças no seu saber-fazer docente. Referiu este professor:

Não é mais do que nós já fazíamos, porque a flexibilização permite a tal flexibilidade. Permite-nos criar mecanismos durante as aulas e o ano letivo. Permite-nos criar eventos, e fazer uma multiplicidade de atividades. A única diferença é que nós temos que criar mais evidências em termos pessoais e profissionais, o que cria mais trabalho burocrático. Para o aluno, não é mais do que alguns professores fazia (PPC1).

Da opinião deste professor depreende-se que, para ele, as mudanças preconizadas no discurso da política curricular correspondem, de fato, a práticas que muitos dos professores já realizavam. É neste mesmo sentido que refere uma professora: "Eu sempre me preocupei em planear as aulas, e adotar as melhores estratégias. O material, não são só os manuais que nos ajudam a dar a aula" (PPC2). A ideia de que esta "nova" medida curricular introduzida pelo PAFC não é, de fato, nova é bem clara no discurso de uma das entrevistadas: "Isto que é feito na flexibilização, nós realmente fazemos. Só que, muitas vezes, não é registado, não é sumariado. Este projeto, eu acho que realmente deve ser trabalhado desde o primeiro ano de escolaridade" (PPC2).

É no movimentum de avanços e recuos que os entrevistados reconhecem os contributos do PAFC para a gestão do currículo na escola, como se infere do que é expresso pela coordenadora do projeto em um dos Agrupamentos de Escolas: "É um passo de cada vez. Pôs as pessoas a discutirem metodologia de trabalho projeto. Temos casos com feedback positivo, por exemplo: a colega que falamos há pouco, ela tem feito práticas muito diferentes dos habituais. E está a reconhecer isso" (CA). 
O reconhecimento de que os docentes são aprendizes sociais desloca a atenção para o entendimento de que as políticas curriculares que pressupõem mudanças e inovação pedagógica propostas verticalmente pelos governos constitucionais são um convite aos professores para a desconstrução de uma concepção arraigada a um currículo prescrito pelo Governo, e de alunos como meros receptores, nos moldes de uma educação tradicional e da valorização do conhecimento dos poderosos (Young, 2014). Ao pensar o lugar do professor como agente de decisão curricular, avaliam-se também as mudanças introduzidas no âmbito geral da escola, como profere a coordenadora deste projeto:

O PAFC não introduziu grandes mudanças a nível da prática. Se me perguntar se, na prática, é isso que acontece eu dir-lhe-ia que não. Embora não tenha evidências concretas, estou neste momento a tentar recolher essas evidências junto dos professores. Temos que apresentar evidências do trabalho realizado e dos contributos para cada aluno e para cada turma (CA).

Estas opiniões de professores que se encontram na concretização das práticas curriculares desvelam percepções significativas, embora tímidas, com relação ao processo de mudança e inovação em contextos de prática. Isto porque mudanças educativas efetivas nos contextos de prática requerem tempo, e estão diretamente relacionadas com a formação pessoal e profissional dos professores, que por sua vez os levam a refletir criticamente sobre a prática e ressignificá-la.

\section{Fatores que limitam o poder de agência proferido pela política}

Como a experiência tem mostrado, em contextos de mudanças e inovação curricular os professores encontram muitas vezes grandes constrangimentos e contradições, pois, entre outros aspectos, são-lhes atribuídas responsabilidades pelos resultados de sucesso e/ou fracasso das políticas curriculares. Alguns dos constrangimentos da medida política em análise no estudo a que este artigo se reporta podem ser inferidos pelo que é dito pelo professor:

Para este ano da fase piloto do projeto, o principal constrangimento foi a falta de diretrizes superiores. Mas foi propositado por ser um projeto piloto. Eles estão à espera que nós demos o feedback para orientar o trabalho. Os principais problemas são a parte prática e de aplicação, e o número de alunos por turma. O número de alunos por turma, sendo elevado, torna um pouco mais complexas determinadas atividades, e a execução e a exequibilidade de algumas atividades. É o principal constrangimento, para além de algumas restrições físicas dos espaços escolares (PPC1). 
Enquanto o discurso da política curricular aponta para mudanças nos contextos de prática como alternativa para a melhoria dos processos educativos na escola, os professores no terreno sofrem constrangimentos decorrentes das condições de trabalho. Desses, são feitas alusões prioritariamente aos aspectos: estruturais, acompanhamentos pedagógicos, processos formativos, e valorização profissional. Face a essa situação, a escola e os professores vão "ensaiando" os ajustes do tempo-curricular para a gestão da flexibilização e autonomia curricular.

Sobre os limites do poder de agência (agency), uma das professoras refere:

Embora no projeto haja flexibilização do horário, podemos adaptar e fazer de forma diferente. Mas, inicialmente, assustou-me. Por exemplo, o cumprir o horário, o cumprir o sumário. Fui aos seminários, congressos, encontros, tive encontros com as colegas da DGEstE (Direção-Geral dos Estabelecimentos Escolares) e comecei a perceber que não tinha que ser tão rigoroso. De início fiquei constrangida, tive dificuldade em gerir o tempo, o currículo e como escrever o sumário (PPC2).

A ausência do tempo para planear as ações é um dos fatores sinalizados, como mostra o que é dito por uma das professoras: "Não tenho tempo, porque são muitos alunos, eu precisava de ter mais apoios, uma professora com mais horas, para conseguir de alguma forma que o aluno também tenha a sua aprendizagem, o seu tempo" (PPC4). Se pretendemos que os professores se assumam como agentes de decisões curriculares, é importante que sejam avaliadas as suas condições de trabalho, criando um elenco de alternativas para se garantir momentos na escola que facilitem a tomada de decisões curriculares, e de planeamento e avaliação das práticas. Apesar disso, as escolas estão a buscar formas de reorganizar o currículo mediante as orientações do PAFC, como foi referido por outro dos entrevistados: "somos um agrupamento TEIP, temos que pensar o que é importante para as crianças. Vamos adaptando. Analisámos o perfil do aluno, e fomos adaptando de acordo com o meio em que estamos inseridos" (PPC4).

Em síntese, apesar dos constrangimentos existentes, os professores buscam alternativas para motivar os colegas, como inferimos dos enunciados:

Estamos a começar o primeiro ano, mudar as práticas. Há a tal resistência de alguns colegas que não estão tão habituadas, e torna-se mais difícil. Depois de as pessoas acharem que é mais divulgado desta forma o trabalho, elas vão aderindo ao PAFC (PPC2). 
Na última reunião que tivemos, e que foi com a coordenadora de departamento, um dos pontos que nós falamos é que temos que alterar o nosso registo de avaliação, porque também a avaliação é um pouco diferente, mas não foi modificada (PPC3).

Como se infere, os professores, em contextos de prática, compartilham as suas experiências com relação ao seu poder de agência nas decisões curriculares, mediante a sua capacidade de reflexão e das oportunidades que têm para a realização da partilha e da colaboração. Em outras palavras, o poder de agência será enriquecido e potencializado pelo amplo repertório de respostas e formas de intervenções nas situações cotidianas às quais podem recorrer no interior da escola (Priestley et al., 2013). Nesses momentos, a escuta sensível das práticas curriculares dos outros, em situações de colaboração, tornam-se modelos e motivação para a mudança, e, muitas vezes, permitem a desconstrução de uma concepção de currículo enquanto apenas listas predefinidas de conteúdos, permitindo pensar, entre outros aspetos, por exemplo, sobre o lugar do manual escolar no contexto do PAFC, como se infere do que é dito pelo professor:

Alguns professores seguiram o manual. E outros deixaram de usar. Deixaram porque ouviram também a experiência dos colegas. Eu fui seguindo o manual, para me orientar nos casos de leitura, as letras, principalmente, o Português. Para o próximo ano, posso começar a tentar mudar (PPC2).

Os conflitos gerados pela exigência do cumprimento de duas orientações curriculares distintas fazem com que, por um lado, os professores se sintam obrigados a cumprir Metas curriculares e, por outro, a flexibilizar o currículo, como também foi referenciado por uma das professoras:

Tive que me adaptar, porque como professora, eu tenho a necessidade de cumprir Metas, de cumprir o programa na sua totalidade. E na escola TEIP isso não é o mais importante. O essencial é o que os alunos levam para a vida. E é muito bom termos a flexibilização. Podemos escolher os conteúdos essenciais. O essencial é pôr as crianças a ler e a escrever (PPC4).

O "novo" enquadramento curricular implica também respeitar as diferentes culturas escolares, seus modos de gerir a construção do currículo local tendo em consideração as necessidades de aprendizagens imediatas dos alunos. Por isso, como reconhecem alguns dos professores, a autonomia e a flexibilização garantidas devem continuar nas orientações curriculares do país, como explicita a professora: 
Eu acho que deveria ser mesmo obrigatório e extensivo a todos os anos de escolaridade esta medida da flexibilização curricular. Embora também como estamos a fazer no agrupamento, aos poucos, também não será má ideia. Mas acho que mudou, e vai mudar mesmo as mentalidades, a forma dos meninos estarem, serem e aprenderem (PPC2).

As políticas curriculares verticais descontínuas são um dos fatores que limitam e, de certo modo, contribuem para que seja construído um clima de descrença, desânimo e coloque constrangimentos aos professores que estão a tentar entender o que de fato se espera dos processos educativos na escola. Como se tornou claro, os sujeitos ouvidos nesta investigação levam-nos a entender os limites que se colocam ao poder de agência, assim como à capacidade que os professores, em contextos de prática, têm para refletirem sobre as situações reais que enfrentam e, face a elas, agirem na busca de estratégias de superação das restrições impostas na/para a gestão curricular nas escolas.

\section{Considerações finais}

O movimentum de construção deste artigo, como referido, teve como foco de pesquisa as aproximações entre o discurso académico que defende o poder agência de decisão curricular dos professores e as opiniões de responsáveis escolares e de professores sobre esse poder que lhes é concedido a partir da medida curricular do Projeto de Autonomia e Flexibilização Curricular (PAFC) em Portugal.

Em sua amplitude, a investigação permitiu construir um conhecimento advindo das respostas às questões de partida: qual a concepção de responsáveis de Agrupamentos de Escolas e de professores sobre os fatores contextuais que dão forma ou estabelecem limites aos professores para se colocarem como agentes de decisões curriculares, papel que é legitimado no discurso da política curricular de Portugal no contexto do PAFC.-

Relativamente aos fatores contextuais que dão forma à possibilidade dos professores serem agentes de decisões curriculares, o estudo mostrou que os entrevistados compreendem: o discurso da Política Curricular do PAFC, nomeadamente que este, ao seguir o princípio de uma certa flexibilização e autonomia, os reconhece no seu poder de agência; o processo de construção, embora ainda com resistência em alguns contextos da prática; a importância de uma cultura de partilha entre os professores; a escola como local de gestão curricular; o currículo como construção cotidiana, enquadrado por orientações emanadas do Ministério da Educação, de que são exemplo as Aprendizagens Essenciais e as Metas curriculares; a necessidade dos conteúdos previstos no currículo serem contextualizados; o 
reconhecimento dos alunos como sujeitos que possuem conhecimentos, que têm ritmos e processos de aprendizagens diferenciados; a justiça curricular como direito a que todos devem aceder.

Em relação aos fatores contextuais que limitam o poder de agência de decisão curricular dos professores, os entrevistados reconhecem: as condições de trabalho na escola (materiais e estruturais); o número excessivo de alunos por turma; as contradições entre duas orientações curriculares assentes, ora nas Aprendizagens Essenciais ora nas Metas curriculares; o processo, ainda em construção, de uma cultura de partilha e colaboração; a compreensão dos professores sobre os pressupostos da referida política e a materialização de ações práticas; o aumento das exigências normativas — mostrar evidências do projeto; e o reconhecimento de que as mudanças levam tempo.

Em síntese, o estudo revela que, em Portugal, o direito ao poder de agência de decisão curricular conferido aos professores pela publicação de uma medida política ainda se encontra em processo de consolidação, desde o seu entendimento até à sua concretização em ações práticas. Isto mostra que o discurso político horizontal se enfraquece à medida que desconsidera quer a formação e a adesão dos professores em contexto, quer os diálogos entre as ações práticas e os discursos teóricos. Por isso, o poder de agência de decisão curricular dos professores ao serviço da justiça curricular (Connell, 1999, 2012; Sampaio \& Leite, 2015, 2018) ainda clama por condições melhores e mais efetivas de trabalho e de valorização profissional, pois o exercício da autonomia e a flexibilidade do currículo concedidos, no campo do discurso político, não garantem per se o poder de agência dos professores, e nem o alcance das aprendizagens para todos os alunos.

\section{Sobre os autores}

Adriana Cavalcanti dos Santos es professora adjunta da Universidade Federal de Alagoas, Brasil. Atua nos quadros permanentes do Programa de Pós-Graduação em Educação (PPGE/CEDU/UFAL) e do Programa de Ensino de Ciências e de Matemática.

Carlinda Leite es professora catedrática da Universidade do Porto, Portugal, na FPCEUP. Supervisiona várias teses de PhD e de investigações de pós-doc. Investigadoira sénior do CIIE.

\section{Referências}

Bakthin, M. (1992). Marxismo e filosofia da linguagem (6. ${ }^{a}$ ed.). São Paulo: Hucitec. Ball, S. (2002). Reformar escolas/reformar professores e os terrores da performatividade. Revista Portuguesa de Educação, 15(2), 3-23. 
Ball, S. (2005). Profissionalismo, gerencialismo e performatividade. Caderno de Pesquisa, 35(126), 539-564.

Bardin, L. (2009). Análise de conteúdo. Lisboa: 70.

Barroso, J. (2004). A autonomia das escolas: uma ficção necessária. Revista Portuguesa de Educação, 17(2), 49-83.

Biesta, G. \& Tedder, M. (2006). How is agency possible? Towards an ecological understanding of agency-as-achievement. Learning lives: Learning, identity, and agency in the life course (working paper five). Exeter: Teaching and Learning Research Programme.

Bolívar, A. (2012). Melhorar os processos e os resultados educativos: o que nos ensina a investigação. Gaia: Fundação Manuel Leão.

Castillo-Alemán, G. del (2012). Las políticas educativas en México desde una perspectiva de política pública: gobernabilidad y gobernanza. Magis, Revista Internacional de Investigación en Educación, 4(9), 637-652. Recuperado de http://revistas.javeriana.edu.co/index.php/MAGIS/article/view/3580

Connell, R. (1999). Escuelas e justicia social. Madrid: Morata.

Connell, R. W. (2012). Just education. Journal of Education Policy, 27(5), 681-683.

Decreto-Lei n. ${ }^{\circ}$ 55/2018, de 6 de julho de 2018, que estabelece o currículo dos ensinos básico e secundário e os princípios orientadores da avaliação das aprendizagens.

Despacho n. ${ }^{\circ}$ 6478/2017, de 26 de julho de 2017, que homologa o perfil dos alunos à saída da escolaridade obrigatória.

Despacho n. ${ }^{\circ}$ 6944-A/2018, de 19 de julho de 2018, que homologa as aprendizagens essenciais do ensino básico.

Despacho n. ${ }^{\circ}$ 5908/2017, de 5 de julho de 2017, que autoriza, em regime de experiência pedagógica, a implementação do projeto de autonomia e flexibilidade curricular dos ensinos básico e secundário, no ano escolar de 2017-2018.

Ferraço, C. E. (2017). Currículo-docência-menor e pesquisas com os cotidianos escolares. Quaestio-Revista de Estudos em Educação, 19(3), 529-546.

Freire, P. (2003). Pedagogia do oprimido. Rio de Janeiro: Paz e Terra.

Gadotti, M. (2010). Escola cidadã. São Paulo: Cortez.

Leite, C. (2003). Para uma escola curricularmente inteligente. Porto: Edições ASA.

Leite, C. (2005). A territorialização das políticas e das práticas educativas. Em C. Leite, Mudanças curriculares em Portugal (pp. 15-32). Porto: Porto.

Leite, C. \& Fernandes, P. (2010). Desafios aos professores na construção de mudanças educacionais e curriculares: que possibilidades e que constrangimentos? Revista Educação, PUCRS, 33(3), 198-204.

Leite, C., Fernandes, P. \& Marques da Silva, S. (2013). O lugar da educação para a cidadania no sistema educativo português: perspectivas de docentes de uma escola TEIP. Revista Educação-PUCRS, 36(1), 35-43.

Leite, C. \& Lascano-Pinto, C. (2016). O trabalho colaborativo entre os professores no quotidiano escolar. Educação, Sociedade \& Culturas, 48, 69-91.

Lima, L. C. (2014). A gestão democrática das escolas: do autogoverno à ascensão de uma pós-democracia gestionária? Educação e Sociedade, 35(129), 1067-1083. 
Mainardes, J. \& Marcondes, M. I. (2009). Entrevista com Stephen J. Ball: um diálogo sobre justiça social, pesquisa e política educacional. Educação e Sociedade, 30(106), 303-318.

Marinho, P., Leite, C. \& Fernandes, P. (2017). Mathematics summative assessment practices in schools at opposite ends of performance rankings in Portugal. Research in Mathematics Education, 19(2), 184-198.

Moreira, A. F. (2013). Currículo e gestão: propondo uma parceria. Revista Ensaio: Avaliação e Políticas Públicas em Educação, 21(80), 547-562.

Pacheco, J. A. \& Sousa, J. (2018). Políticas curriculares no período pós-LBSE (1986-2017): ciclo de mudanças na educação pré-escolar e nos ensinos básicos e secundários. Em J. A. Pacheco, M. C. Roldão \& M. T. Estrela, Estudos

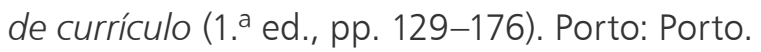

Parra-Mosquera, C. (2016). La escolarización de los saberes: un escenario relevante para rastrear y comprender algunos problemas sociales y humanos contemporáneos. Magis, Revista Internacional de Investigación en Educación, 8(17), 179-186.

Priestley, M., Biesta, G. \& Robinson, S. (2015). Teacher agency: What is it and why does it matter?. Em R. Kneyber \& J. Evers, Flip the System: Changing Education from the Bottom up (pp. 134-148). London: Routledge.

Priestley, M., Biesta, G. \& Robinson, S. (2013). Teachers as agents of charge: Teacher agency and emergigng models of curricum. Em M. Priestley \& G. Biesta, Reiventing the Curriculum: New Trends in Curriculim Police and Practice (pp. 187-206). London: Bloomsbury Academic.

Robertson, S. L. \& Dale, R. (2014). Towards a "critical cultural political economy" account of the globalising of education. Journal Globalisation, Societies and Education, 13(1), 149-170.

Sampaio, M. \& Leite, C. (2015). A territorização das políticas educativas e justiça curricular: o caso TEIP em Portugal. Currículo sem Fronteiras, 15(3), 715-740.

Sampaio, M. \& Leite, C. (2018). Mapping social justice perspectives and their relationship with curricular and schools' evaluation practices: Looking at scientific publications. Education as Change. 22(1), 1-21. Recuperado de http://www.scielo.org.za/pdf/eac/v22n1/02.pdf

Seidman, I. (2013). Interviewing as qualitative research: A guide for researchers in education \& the social sciences. New York: Teachers College.

Trindade, R. \& Cosme, A. (2014). A diferenciação curricular e pedagógica como um desafio epistemológico. Caderno de Pesquisa: Pensamento Educacional, 9(23), 21-42.

Vilelas, J. (2009). Investigação: o processo de construção do conhecimento. Lisboa: Silabo.

Young, M. (2014). Teoria do currículo: o que é e por que é importante? Cadernos de Pesquisa, 44(51), 190-202. 